\section{REVISTA BRASILEIRA DE QUALIDADE DE VIDA}

\title{
Cálculo dos escores e estatística descritiva do WHOQOL-bref através do Microsoft Excel
}

\section{Calculation of scores and descriptive statistics of WHOQOL-bref through Microsoft Excel}

\author{
Bruno Pedroso \\ Universidade Tecnológica Federal do Paraná - UTFPR - Ponta Grossa - Brasil \\ Universidade Estadual de Campinas - UNICAMP - Campinas - Brasil \\ brunops3@brturbo.com.br \\ Luiz Alberto Pilatti \\ Universidade Tecnológica Federal do Paraná - UTFPR - Ponta Grossa - Brasil \\ lapilatti@utfpr.edu.br \\ Gustavo Luis Gutierrez \\ Universidade Estadual de Campinas - UNICAMP - Campinas - Brasil \\ glgutierrez@terra.com.br \\ Claudia Tania Picinin \\ Universidade Tecnológica Federal do Paraná - UTFPR - Ponta Grossa - Brasil \\ claudiapicinin_adm@yahoo.com.br
}

\section{Resumo}

O objetivo do presente trabalho é disponibilizar uma ferramenta, desenvolvida a partir do software Microsoft Excel, direcionada para o cálculo dos escores e estatística descritiva do instrumento WHOQOL-bref - seguindo a sintaxe proposta pelo Grupo WHOQOL. Foram realizadas simulações com dados reais de aplicações do WHOQOL-bref com o software SPSS, em que os resultados obtidos foram exatamente os mesmos. Conclui-se que a disponibilização da presente ferramenta permite realizar aplicações do WHOQOL-bref sem necessitar a utilização do software SPSS.

Palavras-chave: Qualidade de Vida, Organização Mundial da Saúde, WHOQOL-bref.

\begin{abstract}
The objective of this manuscript is to make available a tool developed from Microsoft Excel to calculate the scores and descriptive statistics of WHOQOL-bref instrument, following the syntax proposal by The WHOQOL Group. It was performed simulations with real data of applications of WHOQOL-bref with the software SPSS and the obtained results were exactly the same. It concludes that the distribution of this tool allows the accomplishment WHOQOL-bref's applications without the use of SPSS.
\end{abstract}

Key-words: Quality of Life, World Health Organization, WHOQOL-bref. 


\section{Introdução}

Após a publicação do artigo intitulado "Cálculo dos escores e estatística descritiva do WHOQOL-100 utilizando o Microsoft Excel” (PEDROSO; PILATTI; REIS, 2009), na primeira edição da Revista Brasileira de Qualidade de Vida, foram recebidos vários pedidos de pesquisadores solicitando uma ferramenta, nos mesmos moldes da desenvolvida no manuscrito supracitado, direcionada para o instrumento WHOQOL-bref.

Sob a mesma justificativa anteriormente pautada: a limitação ocasionada pela obrigatoriedade de utilização do software estatístico Statistical Package of Social Sciences (SPSS) um software de elevado custo e que requer conhecimentos específicos para a sua utilização -, e, em face às solicitações proferidas por diversos pesquisadores, surge a proposta de adaptar a ferramenta originalmente construída para o WHOQOL-100, para a sintaxe do WHOQOL-bref. Sendo este, portanto, o objetivo do presente trabalho.

\section{O instrumento WHOQOL-bref}

Com o objetivo de disponibilizar um instrumento que demande menor tempo para preenchimento e com características psicométricas satisfatórias, o Grupo WHOQOL desenvolveu a versão abreviada do WHOQOL-100, o WHOQOL-bref (THE WHOQOL GROUP, 1996).

O WHOQOL-bref é composto por 26 questões, sendo duas questões sobre a auto-avaliação da qualidade de vida e 24 questões representando cada uma das facetas do WHOQOL-100. Para a composição das questões do WHOQOL-bref foi selecionada a questão de cada faceta que apresentava a maior correlação com o escore médio de todas as facetas (THE WHOQOL GROUP, 1998a).

Após a seleção das questões, foi realizada uma análise para verificar se estas, factualmente, representavam as facetas correspondentes. Em seis facetas, a questão selecionada foi substituída por outra questão da faceta correspondente, pois, sob o viés de experts, havia outra questão que melhor definisse essas seis facetas (THE WHOQOL GROUP, 1998a). As facetas pertencentes ao domínio Nível de Independência foram incorporadas ao domínio Físico, assim como a faceta pertencente ao domínio Aspectos espirituais/Religião/Crenças pessoais foi incorporada ao domínio Psicológico. Assim, o WHOQOL-bref é composto por quatro domínios: Físico, Psicológico, Relações Sociais e Meio-Ambiente, perfazendo configuração expressa no Quadro 1:

\begin{tabular}{|c|c|}
\hline DOMÍNIOS & FACETAS \\
\hline \multirow{7}{*}{ Domínio I - Domínio físico } & 1. Dor e desconforto \\
\hline & 2. Energia e fadiga \\
\hline & 3. Sono e repouso \\
\hline & 4. Mobilidade \\
\hline & 5. Atividades da vida cotidiana \\
\hline & 6. Dependência de medicação ou de tratamentos \\
\hline & 7. Capacidade de trabalho \\
\hline \multirow{6}{*}{ Domínio II - Domínio psicológico } & 8. Sentimentos positivos \\
\hline & 9. Pensar, aprender, memória e concentração \\
\hline & 10. Auto-estima \\
\hline & 11. Imagem corporal e aparência \\
\hline & 12. Sentimentos negativos \\
\hline & 13. Espiritualidade/religião/crenças pessoais \\
\hline \multirow{3}{*}{ Domínio III - Relações sociais } & 14. Relações pessoais \\
\hline & 15. Suporte (Apoio) social \\
\hline & 16. Atividade sexual \\
\hline \multirow{3}{*}{ Domínio IV- Meio-Ambiente } & 17. Segurança física e proteção \\
\hline & 18. Ambiente no lar \\
\hline & 19. Recursos financeiros \\
\hline
\end{tabular}


20. Cuidados de saúde e sociais: disponibilidade e qualidade

21. Oportunidades de adquirir novas informações e habilidades

22. Participação em, e oportunidades de recreação/lazer

23. Ambiente físico: (poluição/ruído/trânsito/clima)

24. Transporte

Quadro 1: Domínios e facetas do WHOQOL-bref

Fonte: The WHOQOL Group (1998a)

Tendo por base os quatro domínios supracitados, as questões que compõem o WHOQOLbref, com as questões cuja escala de respostas é invertida grafadas em itálico, são as seguintes:

\begin{tabular}{|c|c|}
\hline DOMÍNIOS & QUESTÕES \\
\hline \multirow{7}{*}{ Domínio I - Físico } & $\begin{array}{l}\text { Em que medida você acha que sua dor (física) impede você de fazer } \\
\text { o que você precisa? }\end{array}$ \\
\hline & Você tem energia suficiente para seu dia-a-dia? \\
\hline & Quão satisfeito(a) você está com o seu sono? \\
\hline & Quão bem você é capaz de se locomover? \\
\hline & $\begin{array}{l}\text { Quão satisfeito(a) você está com sua capacidade de desempenhar as } \\
\text { atividades do seu dia-a-dia? }\end{array}$ \\
\hline & $\begin{array}{l}\text { O quanto você precisa de algum tratamento médico para levar sua } \\
\text { vida diária? }\end{array}$ \\
\hline & Quão satisfeito(a) você está com sua capacidade para o trabalho? \\
\hline \multirow{6}{*}{ Domínio II - Psicológico } & O quanto você aproveita a vida? \\
\hline & O quanto você consegue se concentrar? \\
\hline & Em que medida você acha que a sua vida tem sentido? \\
\hline & Você é capaz de aceitar sua aparência física? \\
\hline & $\begin{array}{l}\text { Com que freqüência você tem sentimentos negativos tais como mau } \\
\text { humor, desespero, ansiedade, depressão? }\end{array}$ \\
\hline & Quão satisfeito(a) você está consigo mesmo? \\
\hline \multirow{3}{*}{$\begin{array}{l}\text { Domínio III - Relações } \\
\text { Sociais }\end{array}$} & $\begin{array}{l}\text { Quão satisfeito(a) você está com suas relações pessoais (amigos, } \\
\text { parentes, conhecidos, colegas)? }\end{array}$ \\
\hline & $\begin{array}{l}\text { Quão satisfeito(a) você está com o apoio que você recebe de seus } \\
\text { amigos? }\end{array}$ \\
\hline & Quão satisfeito(a) você está com sua vida sexual? \\
\hline \multirow{8}{*}{ Domínio IV - Meio-ambiente } & Quão seguro(a) você se sente em sua vida diária? \\
\hline & Quão satisfeito(a) você está com as condições do local onde mora? \\
\hline & Você tem dinheiro suficiente para satisfazer suas necessidades? \\
\hline & $\begin{array}{l}\text { Quão satisfeito(a) você está com o seu acesso aos serviços de } \\
\text { saúde? }\end{array}$ \\
\hline & $\begin{array}{l}\text { Quão disponíveis para você estão as informações que precisa no seu } \\
\text { dia-a-dia? }\end{array}$ \\
\hline & Em que medida você tem oportunidades de atividade de lazer? \\
\hline & $\begin{array}{l}\text { Quão saudável é o seu ambiente físico (clima, barulho, poluição, } \\
\text { atrativos)? }\end{array}$ \\
\hline & Quão satisfeito(a) você está com o seu meio de transporte? \\
\hline \multirow{2}{*}{$\begin{array}{l}\text { Qualidade de vida global e } \\
\text { percepção geral da saúde }\end{array}$} & Como você avaliaria sua qualidade de vida? \\
\hline & Quão satisfeito(a) você está com a sua saúde? \\
\hline
\end{tabular}

Quadro 2: Questões do WHOQOL-bref

Fonte: Adaptado de Grupo WHOQOL (1998)

O cálculo dos escores do WHOQOL-bref segue a mesma lógica do WHOQOL-100, exceto pelo cálculo dos escores das facetas. No WHOQOL-bref cada faceta é representada por uma única 
questão, e, por esse motivo, os escores das facetas não são calculados (THE WHOQOL GROUP, 1996). A sintaxe para o cálculo dos resultados do WHOQOL-bref é a seguinte:

\begin{tabular}{|c|c|}
\hline ETAPAS & $\begin{array}{l}\text { SINTAXE SPSS PARA O CÁLCULOS DOS ESCORES DO WHOQOL- } \\
\text { BREF }\end{array}$ \\
\hline $\begin{array}{l}\text { Verificar se todos os } 26 \\
\text { itens foram preenchidos } \\
\text { com respostas entre } 1 \text { e } 5\end{array}$ & $\begin{array}{l}\text { RECODE Q1 Q2 Q3 Q4 Q5 Q6 Q7 Q8 Q9 Q10 Q11 Q12 Q13 Q14 Q15 Q16 } \\
\text { Q17 Q81 Q19 Q20 Q21 Q22 Q23 Q24 Q25 Q26 }(1=1)(2=2)(3=3)(4=4)(5=5) \\
\text { (ELSE=SYSMIS). }\end{array}$ \\
\hline $\begin{array}{l}\text { Converter as questões } \\
\text { invertidas }\end{array}$ & RECODE Q3 Q4 Q26 $(1=5)(2=4)(3=3)(4=2)(5=1)$. \\
\hline $\begin{array}{l}\text { Calcular os escores dos } \\
\text { domínios }\end{array}$ & $\begin{array}{l}\text { COMPUTE PHYS=MEAN.6(Q3,Q4,Q10,Q15,Q16,Q17,Q18)*4. } \\
\text { COMPUTE PSYCH=MEAN.5(Q5,Q6,Q7,Q11,Q19,Q26)*4. } \\
\text { COMPUTE SOCIAL=MEAN.2(Q20,Q21,Q22)*4. } \\
\text { COMPUTE ENVIR=MEAN.6(Q8,Q9,Q12,Q13,Q14,Q23,Q24,Q25)*4. }\end{array}$ \\
\hline $\begin{array}{l}\text { Transformar os escores } \\
\text { para uma escala de } 0 \text { a } \\
100\end{array}$ & $\begin{array}{l}\text { COMPUTE PHYS }=(\text { PHYS }-4) *(100 / 16) \\
\text { COMPUTE PSYCH }=(\text { PSYCH- } 4) *(100 / 16) \\
\text { COMPUTE SOCIAL }=(\text { SOCIAL- } 4) *(100 / 16) \\
\text { COMPUTE ENVIR }=(\text { ENVIR- } 4) *(100 / 16)\end{array}$ \\
\hline $\begin{array}{l}\text { Excluir os respondentes } \\
\text { cujo número de itens não } \\
\text { respondidos excedem } \\
20 \% \text { do total de itens }\end{array}$ & $\begin{array}{l}\text { COUNT TOTAL=Q1 TO Q26 (1 THRU 5). } \\
\text { SELECT IF (TOTAL>=21). } \\
\text { EXECUTE. }\end{array}$ \\
\hline
\end{tabular}

Quadro 3: Sintaxe SPSS para o cálculo dos escores do WHOQOL-bref Fonte: The WHOQOL Group (1998b)

A transcrição textual da sintaxe do WHOQOL-bref se apresenta da seguinte forma:

- É verificado se todas as 26 questões foram preenchidas com valores entre 1 e 5;

- Invertem-se todas as questões cuja escala de respostas é invertida;

- Os escores dos domínios são calculados através da soma dos escores da média da " $n$ " questões que compõem cada domínio. Nos domínios compostos por até sete questões, este será calculado somente se o número de facetas não calculadas não for igual ou superior a dois. Nos domínios compostos por mais de sete questões, este será calculados somente se o número de facetas não calculadas não for igual ou superior a três. $O$ resultado é multiplicado por quatro, sendo representado em uma escala de 4 a 20;

- Os escores dos domínios são convertidos para uma escala de 0 a 100;

- Os respondentes que deixaram de preencher ou preencheram incorretamente mais do que seis questões ( $80 \%$ do total de questões do instrumento) serão excluídos da amostra.

\section{A ferramenta proposta}

A ferramenta construída no presente estudo segue as mesmas diretrizes da proposta por Pedroso, Pilatti e Reis (2009), realizando os cálculos dos escores e estatística descritiva do WHOQOL-bref de forma automatizada, cabendo ao pesquisador apenas tabular os dados coletados na aplicação do WHOQOL-bref. Nessa perspectiva, a lógica utilizada pela ferramenta é a seguinte: 
- As células cujas respostas estão corretas (respondidas com valores situados no intervalo compreendido entre 1 e 5) são representadas através da cor de preenchimento verde;

- Caso algum respondente tenha deixado de responder seis ou mais questões, o pesquisador será instruído para excluir tal respondente. O número de questões não respondidas é informado ao pesquisador e as questões não respondidas estarão em destaque (cor do preenchimento branco);

- Caso alguma resposta tenha sido preenchida com algum valor que não conste entre o intervalo de 1 a 5, o número de respostas inválidas será notificado ao pesquisador e as respostas inválidas estarão em destaque (cor do preenchimento vermelho);

- As questões de escala invertida são devidamente convertidas;

- Em domínios compostos por até sete questões, se duas ou mais questões pertencentes ao mesmo domínio não tiverem sido preenchidas corretamente, o escore desse domínio não será calculado. Em domínios compostos por mais de sete questões, se três ou mais questões pertencentes a este domínio não tiverem sido preenchidas corretamente, o escore desse domínio não será calculado;

- Caso dois ou mais domínios não sejam calculados, o pesquisador é instruído a excluir o respondente da amostra;

- É calculado um escore "Total" do respondente. Proposto neste trabalho, tal escore consiste no cálculo da média aritmética simples dos escores das 26 questões do instrumento;

- A estatística descritiva de cada questão (faceta), domínio e "Total" é calculada. Os valores apresentados na estatística descritiva são: média, desvio padrão, valor máximo, valor mínimo, coeficiente de variação e amplitude;

- As médias dos escores das questões (facetas) e domínios são convertidas em uma escala de 0 a 100, e são exibidas em um gráfico.

É permitido ao pesquisador copiar os escores individuais de cada respondente, resultados da estatística descritiva e gráficos. É mantida a restrição que não permite a modificação dos resultados, sendo que a única área em que é permitida a inserção e edição de valores é a área de tabulação das respostas dos respondentes.

Tal qual a ferramenta proposta por Pedroso, Pilatti e Reis (2009), esta fora testada em diferentes versões do software Microsoft Office (2000, XP, 2003 e 2007). Foram realizadas, também, simulações com dados reais de aplicações do WHOQOL-bref, comparando os resultados obtidos através da ferramenta proposta com os obtidos no SPSS. Não houve divergência nos resultados retornados por ambos os softwares.

O download da ferramenta pode ser realizado através da URL: http://www.brunopedroso.com.br/whoqol-bref.html.

\section{Considerações finais}

Ainda que os instrumentos WHOQOL sejam amplamente utilizados e difundidos, a utilização do software SPSS para o cálculo dos resultados destes constitui um fator limitante na sua utilização.

Almejando a supressão dessa limitação, o presente pautou-se em construir uma ferramenta, a partir do software Microsoft Excel, para a realização do cálculo dos escores e estatística descritiva do WHOQOL-bref.

A ferramenta foi testada em diferentes versões do Microsoft Excel - 2000, XP, 2003 e 2007 - e, também, foram comparados os resultados retornados pela ferramenta proposta com os retornados pelo SPSS. Os resultados obtidos foram idênticos aos da sintaxe proposta pela OMS para o software SPSS, em todas as versões do Microsoft Excel testadas.

Nessa perspectiva, conclui-se que fora possível a disponibilização de uma ferramenta fidedigna para os cálculos dos escores e estatística descritiva do instrumento WHOQOL-bref, 
construída a partir de uma plataforma amplamente difundida e de menor complexidade de utilização.

\section{Referências}

GRUPO WHOQOL. Versão em português dos instrumentos de avaliação da qualidade de vida (WHOQOL). Faculdade de Medicina da UFRGS, 1998. Departamento de Psiquiatria. Disponível em: <http://www.ufrgs.br/psiq/whoqol1.html>. Acesso em: 13 abr. 2008.

PEDROSO, B.; PILATTI, L. A.; REIS, D. R. Cálculo dos escores e estatística descritiva do WHOQOL-100 utilizando o Microsoft Excel. Revista Brasileira de Qualidade de Vida, Ponta Grossa, v. 1, n. 1, p. 23-32, jan./ jul. 2009.

THE WHOQOL GROUP. WHOQOL-bref: introduction, administration, scoring and generic version of assessment. Geneva: World Health Organization, 1996.

THE WHOQOL GROUP. Development of the World Health Organization WHOQOL-BREF Quality of Life Assessment. Psychological Medicine, Cambridge, UK, v. 28, n. 3, p. 551-558, may 1998a.

THE WHOQOL GROUP. WHOQOL user manual. Geneva: World Health Organization, $1998 \mathrm{~b}$. 